\title{
Stakeholder and Public Involvement in Risk Governance
}

\author{
Ortwin Renn
}

Published online: 25 February 2015

(C) The Author(s) 2015. This article is published with open access at Springerlink.com

\begin{abstract}
Stakeholder involvement has been a major requirement for effective, efficient, and fair risk governance. Since risk management includes uncertain outcomes that affect different parts of the population to different degrees it is essential to integrate the knowledge, values, and interests of stakeholders into the risk policy making process. The article provides insights into how to structure and organize stakeholder participation and how to cope with the challenges of complexity, uncertainty, and ambiguity. For each of the three challenges there is a need for specific input from stakeholders. The article describes these requirements and explains the formats that have been tested for providing this input to the risk governance process.
\end{abstract}

Keywords Participatory formats $\cdot$ Public participation $\cdot$ Risk governance $\cdot$ Stakeholder involvement

\section{Introduction}

In 2006, the International Risk Governance Council (IRGC) published a white paper on risk governance that proposed an analytic framework to structure the complex process of risk governance. This framework offers a conceptual approach for describing and studying risk governance, as well as a guideline on how to improve decisionmaking and risk handling (IRGC 2005; Renn 2008; van Asselt and Renn 2011; Klinke and Renn 2012).

\section{O. Renn ( $\square)$}

Economic and Social Sciences Department and Stuttgart Research Center for Interdisciplinary Risk and Innovation Studies, University of Stuttgart, 70174 Stuttgart, Germany e-mail: ortwin.renn@sowi.uni-stuttgart.de
The governance process according to IRGC's white paper breaks down into different phases. Most risk managers are familiar with the first phase, which aims to frame and define the context and underlying conditions (called "pre-assessment" by IRGC), and the second phase involves assessing facts and concerns (which IRGC calls "appraisal"). The IRGC stresses the need to complete careful risk "characterization" and "evaluation" after confirming the outcome of a risk appraisal, but before proceeding to decisions about risk management. In addition, and central to the risk governance process, communication is cited as an important companion to all phases. In all these phases, stakeholder involvement may help risk assessors and risk managers to improve their performance and to be responsive to societal needs at each stage of the governance process. Figure 1 provides an illustration of the IRGC framework.

Risk communication is featured at the center of the IRGC framework. Effective communication is the prerequisite for stakeholder involvement-not a substitute. It can provide the knowledge base on which the dialogue with stakeholders can become productive. Stakeholder involvement then goes beyond communication. It can ensure, on one hand, that knowledge, interests, and values (as well as worldviews of stakeholders) are incorporated and given their due in the governance process. On the other hand, stakeholders are important agents for disseminating the results of the governance process and facilitating outreach along the way of the governance process.

As risk management has become a major activity of private and public actors that affect the well-being of the entire population, it is mandatory to ensure that all relevant knowledge pools, public values, and social interests are integrated in the governance process (Klinke and Renn 2014). The request for an inclusive governance model for 


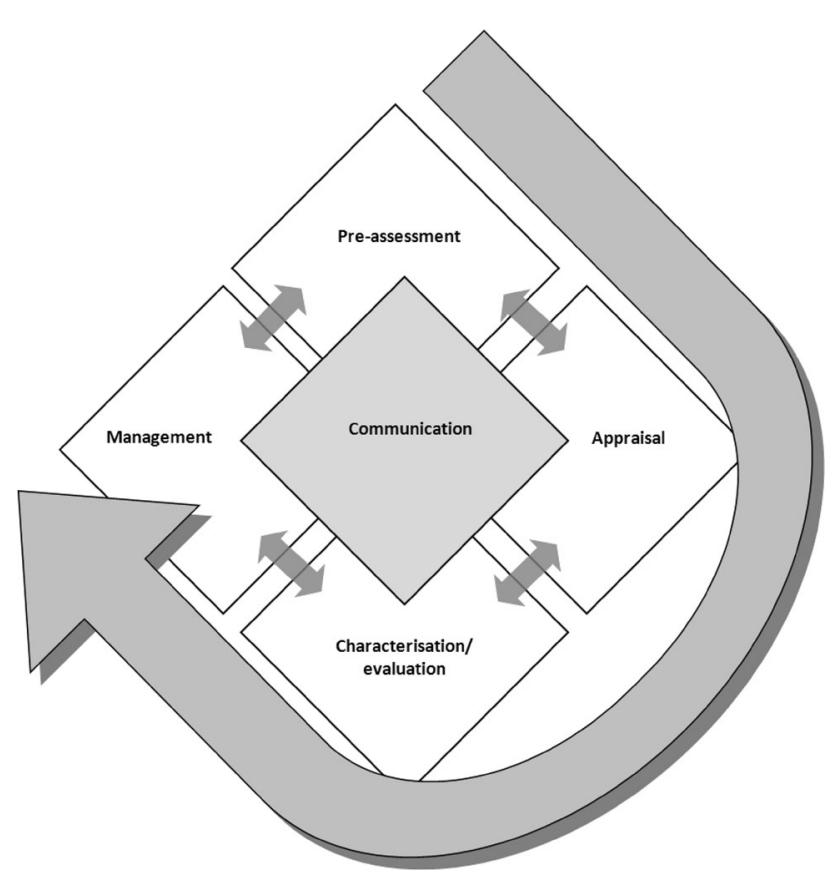

Fig. 1 The five elements of risk governance (reproduced, with permission, from the IRGC (2007))

risk management has been echoed in almost all countries of the world, independent of the political system. It seems wise to incorporate the values and preferences of those who are affected by risk decisions as these groups and individuals will later experience the outcomes of the risk decisions. Furthermore, as collective risk taking requires legitimization it is also politically prudent to integrate stakeholders in the decision-making process (Renn and Schweizer 2009).

The article will address the question of how stakeholder involvement can best be integrated into the risk governance process. Section 2 introduces the three main challenges of risk governance: complexity, uncertainty, and ambiguity and delineates the main requirements for structuring public involvement programs. In Sect. 3 a typology of discourses (the so-called risk governance escalator) is introduced that helps to match discourse method and purpose with each of the three challenges. How to meet these communication and participation demands in each phase of the risk governance cycle is the main topic of Sect. 4. Section 5 provides a review of formats that one can select for each discourse purpose. The conclusions summarize the results and describe the potential of stakeholder involvement in science-based policy arenas.

\section{The Special Features of Risk: Complexity, Uncertainty, and Ambiguity}

What is so special about stakeholder involvement in the domain of risk governance? Decision-making on risk faces three major challenges that make decision-making more difficult: complexity, uncertainty, and ambiguity (Renn et al. 2011; van Asselt and Renn 2011). Some risk situations are simple in structure, the probabilities of harm are well understood, and the risks (as well as risk reduction measures) are noncontroversial. These are referred to as linear risks. All other types of risks are combinations of complexity, uncertainty, and ambiguity. What do we mean with these terms?

- Complexity: Complexity is given when many intervening factors affect the causal relationship between a cause and an effect. Complexity requires sophisticated modeling, which often defies common sense or intuitive reasoning. Yet, if the causal or functional relationships between and among the variables are sorted out and empirically tested, it produces a high degree of confidence in the results. Examples for complex risk issues are the health consequences of toxic substances, the modeling of climate change, or the investment in novel financial products such as derivatives.

- Uncertainty: Uncertainty reduces confidence in the estimated cause-and-effect chain. Risk-based decisions must carefully consider any uncertainties, which characterize both the benefits and the risks. Uncertainty is not a sign of poor science or inadequate calculations. It represents the best available knowledge at a specific point in time. Often, science can set boundaries between a lower and an upper limit of what can reasonably be expected. Highly uncertain risks include many environmental stressors, the occurrence of natural disasters such as earthquakes, or the aggregate result of many financial transactions.

- Ambiguity: Ambiguity arises when differences exist in how individual actors or stakeholders value some input or outcome of the risk-related events. It is based on the question of what our knowledge on risks means for understanding the effects of the risk agent on human health and the environment (interpretative ambiguity), and what kind of decisions or actions are justified once the risks and uncertainties are characterized (normative ambiguity). A condition of ambiguity emerges where the problem lies in agreeing on the appropriate values, priorities, assumptions, or boundaries to be applied to the definition of possible outcomes. For example, what does it mean, if neuronal activities in the human brain are intensified when subjects are exposed to electromagnetic radiation? Can this be interpreted as an adverse effect, or is it just a bodily response without any health implications? Many scientific disputes in the fields of risk assessment and management do not refer to differences in methodology or measurements, but to the question of what all of this means for human health 
and environmental protection (Horlick-Jones 1998). In risk governance, ambiguity plays an important role because plural knowledge and value inputs are difficult to reconcile, and overarching arguments, which might lead to a consensus, are hard to find or to approve by all parties. Typical risks with high ambiguity are biological hazards such as viruses and bacteria, medical practices such as therapeutic cloning, agricultural technologies such as genetic modification, and the deregulation of financial markets.

Most risks are characterized by a mixture of complexity, uncertainty, and ambiguity. Passive smoking may be a good example of low complexity and uncertainty, but high ambiguity. Nuclear energy may be a good candidate for high complexity and high ambiguity, but relatively little uncertainty. Endocrine disrupters could be cited as examples for high complexity, uncertainty, and ambiguity. The following sections will use the distinction of complexity, uncertainty, and ambiguity to derive the best strategies for stakeholder involvement.

\section{The Stakeholder Involvement Escalator}

Depending on the combination of complexity, uncertainty, and ambiguity, different levels of stakeholder participation seem appropriate to guarantee the quality of the participation process. Four types of "discourses" describing the extent of participation are suggested in accordance with the risk governance framework and outlined below (Renn 2008, p. 280; Renn 2014, p. 54ff).

\subsection{Type 1: Linear Risks}

Dealing with linear risk issues (which are associated with low scores for complexity, scientific uncertainty, and sociopolitical ambiguity), requires hardly any changes to conventional public policy-making. The data and information regarding such linear (routine) risk problems are provided by statistical analyses, law or statutory requirements determine the general and specific objectives, and the role of public policy is to ensure that all necessary safety and control measures are implemented and enforced. Traditional cost-benefit analyses, including effectiveness and efficiency criteria, are the instruments of political choice for finding the right balance between under- and overregulation of risk-related activities and goods. In addition, monitoring is important to help prevent unexpected consequences. Linear risk issues can well be handled by departmental and agency staff and enforcement personnel of state-run governance institutions. The aim is to find the most cost-effective method for a desired regulation level. If necessary, stakeholders may be included in the deliberations as they have information and know-how that may help to make the measures more efficient.

\subsection{Type 2: Complex Risks}

Resolving complex risk problems requires dialogue and deliberation among experts. The main goal is to scan and review existing knowledge about the causal connections between an agent and potential consequences, to characterize the uncertainty of this relationship, and to explore the evidence that supports these inferences. Involving members of various communities that demonstrate expertise and competence is the most promising step for producing more reliable and valid judgments about the complex nature of a given risk. With respect to the analytic-deliberative model of involvement, complex issues place most weight on the analytic part, trying to develop functional solutions to problems. The objective of such an involvement process is to find the most cogent description and explanation of the complexity in question, as well as a clarification of dissenting views (for example, by addressing the question of which environmental and socioeconomic impacts are to be expected, in which areas, and in what time frame). The deliberation among experts might generate a profile of the complexity of the given risk issue based on selected intersubjectively chosen criteria. The deliberation may also reveal that there is more uncertainty and ambiguity hidden in the case than the initial appraisers had anticipated. It is advisable to include natural as well as social scientists in such an epistemic discourse so that potential problems with risk perceptions and social concerns can be anticipated. Controversies would then be less of a surprise than is currently the case.

\subsection{Type 3: High Uncertainty}

Characterizing and evaluating risks_-as well as developing appropriate options for risk reduction and control in situations of high uncertainty-poses particular challenges. How can risk managers characterize and evaluate the severity of a risk problem when the potential damage and its probability are unknown or highly uncertain? Scientific input is, therefore, only the first step in a series of steps constituting a more sophisticated evaluation process. It is crucial to compile the relevant information about the different types of uncertainties to inform the process of risk characterization.

The outcome of the risk characterization process provides the foundation for broader deliberation in which not only policy-makers and scientists but also directly affected stakeholders and public interest groups ought to be 
involved. In this way they can discuss the "right" balances and trade-offs between over- and underprotection against risks. Within the analytic-deliberative model of stakeholder involvement, the deliberation forum is the best arena to address issues of uncertainty. The involvement of stakeholders pursues the purpose of finding a consensus on the extra margin of safety that potential victims would be willing to tolerate and in which potential beneficiaries of the risk would be willing to invest to avoid potentially critical and catastrophic consequences. If too much precaution is applied, innovations may be impeded or even eliminated; if too little precaution is applied, society may experience the occurrence of undesired consequences. The crucial question here is how much uncertainty and ignorance the main stakeholders are willing to accept or tolerate in exchange for some potential benefit. This type of deliberative discourse is referred to as "reflective."

\subsection{Type 4: High Ambiguity}

If risk problems are associated with high ambiguity, it is not enough to demonstrate that risk management or regulation addresses the public concerns of those directly affected. In these cases, the process of evaluation needs to be open to public scrutiny and new forms of deliberation. This starts with revisiting the question of proper framing. Is the issue really a risk problem or is it an issue of lifestyle or future vision? Often the benefits are contested in addition to the risks.

The debate regarding "designer babies" illustrates the point that observers may be concerned not only about the social risks of intervening in the genetic code of humans, but also about the acceptability of the desired goal to improve the performance of individuals. Thus, the controversy is often much broader than dealing with direct risks only. The aim is to find an overlapping consensus on the dimensions of ambiguity that need to be addressed in comparing risks and benefits, and balancing pros and cons. High ambiguity would require the most inclusive strategy for involvement because not only directly affected groups but also those indirectly affected should have an opportunity to contribute to the debate.

Resolving ambiguities in risk debates requires the participatory involvement of a broad range of stakeholders to openly discuss competing arguments, beliefs, and values. Discussions on high ambiguity have been labelled as "participatory" to echo the need for broad public inclusion. Participatory involvement offers opportunities to resolve conflicting expectations through a process of identifying overarching common values, and to define options that will allow a desirable lifestyle without compromising the vision of others.
3.5 Overview of the Different Stakeholder Involvement Requirements

An overview of the different stakeholder involvement requirements is shown in Fig. 2. The purpose of this schematic overview is to provide a general orientation and to make a generic distinction between ideal cases, not to offer a strict recipe for participation. It may, for instance, be wise to distinguish between different types of risks and different types of regulatory cultures or styles.

\section{Allocation of Stakeholder Involvement for Each Risk Governance Phase}

The classification shown in Fig. 2 offers a simple but powerful set of requirements for stakeholder inclusion based on the characteristics of risk knowledge. These general guidelines can be further specified by looking into each phase of the risk governance cycle (Dreyer and Renn 2009; Renn 2014, p. 58ff).

\subsection{Stakeholder Engagement During Pre-Assessment}

In keeping with the purpose of the pre-assessment phase, the goal of stakeholder engagement here focuses on the initial framing of the problem-defining boundary conditions, as well as the applicable scientific, political, and social conventions, and making a preliminary assessment of the nature of the complexities, uncertainties, and normative ambiguities that decision-makers are likely to face (Entman 1993). The main function in this phase is selection (of information, process steps, and so on) and prioritysetting (what comes first, and what needs to be addressed and in what sequence). These choices demand good insight into the problem area and a legitimate procedure of defining and justifying selection rules and priorities. Organized stakeholders in this phase can contribute their experience with the problem at hand, and may point towards desired time frames, potential urgencies, and nonobvious applications. This discussion between risk regulators, experts, and stakeholders is, therefore, focused on the design of the risk governance phases that are to follow.

\subsection{Stakeholder and Public Engagement During Appraisal}

During the risk appraisal stage, the focus of discussions and debate is on the contribution of knowledge or understanding about the limits of knowledge and about the risk(s) being evaluated. Depending upon the issue at hand, both technical experts (senior risk assessors, scientists, 
Fig. 2 The risk management escalator and stakeholder involvement (reproduced, with permission, from the IRGC (2005))
STAKEHOLDER INVOLVEMENT

\begin{tabular}{|c|c|c|c|c|}
\hline \multirow{4}{*}{ Actors } & & & & "Civil society" \\
\hline & & & $\begin{array}{l}\text { Affected } \\
\text { stakeholders }\end{array}$ & $\begin{array}{l}\text { Affected } \\
\text { stakeholders }\end{array}$ \\
\hline & & $\begin{array}{l}\text { Scientists/ } \\
\text { Researchers }\end{array}$ & $\begin{array}{l}\text { Scientists/ } \\
\text { Researchers }\end{array}$ & $\begin{array}{l}\text { Scientists/ } \\
\text { Researchers }\end{array}$ \\
\hline & Actors & Actors & Actors & Actors \\
\hline $\begin{array}{l}\text { Type of } \\
\text { participation }\end{array}$ & $\begin{array}{l}\text { Instrumental } \\
\text { Find the most } \\
\text { cost-effective } \\
\text { way to make the } \\
\text { risk acceptable } \\
\text { or tolerable }\end{array}$ & $\begin{array}{l}\text { Epidemic } \\
\text { Use experts to } \\
\text { find valid, } \\
\text { reliable and } \\
\text { relevant } \\
\text { knowledge } \\
\text { about the risk }\end{array}$ & $\begin{array}{l}\text { Reflective } \\
\text { Involve all } \\
\text { affected } \\
\text { stakeholders to } \\
\text { collectively } \\
\text { decide best way } \\
\text { forward }\end{array}$ & $\begin{array}{l}\text { Participative } \\
\text { Include all } \\
\text { actors so as to } \\
\text { expose, accept, } \\
\text { discuss and } \\
\text { resolve } \\
\text { differences }\end{array}$ \\
\hline \multirow[t]{2}{*}{$\begin{array}{l}\text { Dominant risk } \\
\text { characteristics }\end{array}$} & Simple & Complexity & Uncertainty & Ambiguity \\
\hline & & $\begin{array}{l}\text { the level of } \mathrm{kr} \\
\text { the type of } \mathrm{pa}\end{array}$ & $\begin{array}{l}\text { edge changes, so } \\
\text { pation need to } \mathrm{ch}\end{array}$ & \\
\hline
\end{tabular}

engineers, economists, and other specialists) and stakeholders (affected communities, industries, and governments) can offer valuable input into assessing risks and their related uncertainties, and possible approaches to evaluating their impacts on different targets. The experience of local communities possibly affected by a risk, or of engineers involved in the design of manufacturing processes and so on, can also provide important input. It is not the task of stakeholders at the appraisal stage to deal with questions relating to the tolerability of the risk or risk management options. These issues are part of the evaluation and management phases. The input into this phase is restricted to knowledge in a wider sense. It includes systematic knowledge provided by scientists and experts, experiential knowledge provided by those who have gained familiarity with the problem (for example, plant operators or consumers of specific products), and local and circumstantial knowledge that may come from a local community or special group (Renn 2010). The focus on knowledge has been described by the term "epistemic discourse" for this type of deliberation (Renn and Schweizer 2009).

\subsection{Stakeholder and Public Engagement During Risk Characterization and Evaluation}

In this phase of the framework, discourse depends upon the nature of the risk characteristics. For linear and complex risks without major uncertainties and ambiguities, an instrumental discourse is sufficient. In this case, existing guidelines or legal prescriptions are probably available to judge the tolerability or acceptability of the risk under consideration. This changes dramatically if the risks are highly uncertain or even ambiguous. Under these circumstances, existing laws and existing standards and guidelines will not be sufficient to make tolerability and acceptability judgments since the impacts are uncertain and contested. More advanced forms of discourse are required. The purpose of stakeholder engagement is to ensure that all values and preferences are made clear to the decision-makers ultimately responsible for deciding what to do about a risk.

In cases of high uncertainty and low to medium ambiguity, the same kinds of stakeholders who were engaged during the pre-assessment phase should be reconvened to consider the new knowledge from the risk and concern assessments and to draw normative conclusions about the risk in consideration. The main aim here is to gain a balanced view on the positive and negative sides of the riskcausing activity or event. This balance is best accomplished if those stakeholders who will have to live with the consequences of the risk management decisions can add their trade-offs and preferences to the final risk tolerability or acceptability judgment. If the risk is highly contested and associated with a high degree of ambiguity, other representatives from the public need to be included-particularly those who will be affected by the risk management decision. The more uncertain and ambiguous the risk situation is, the more deliberation is necessary in order to find the right balance when judging the acceptability of a given risk or risk reduction measures. The focus on making trade-offs between different categories of risks and benefits 
has been described by the term "reflective discourse" for this type of deliberation (Renn and Schweizer 2009).

\subsection{Stakeholder and Public Engagement During the Management Phase}

Stakeholders should be included to help identify, assess, and select different management measures for reducing and managing risks that are not acceptable. The purpose of this part of the discussion is to look at the variety of possible interventions, to address the pros and cons for each measure or package of measures, and to suggest a set of measures that appear to be effective, efficient, and fair. Both relevant knowledge and different preferences need to be considered when selecting one or more management measures. The aim in this phase is to provide input for a regulatory impact assessment, since regulatory measures normally affect other aspects (which people value) in addition to risk reduction.

It may be costly to society to implement risk reduction measures, it may add unnecessary bureaucracy, it may cause more inequity, and it may lead to non-sustainable practices. These impacts need to be assessed in order to balance the goal of risk reduction with the costs of accomplishing this reduction. For identifying and weighing these impacts, it is important to understand how different stakeholders experience these impacts. The focus on making choices between different management options has been described by the term "participatory discourse" for this type of deliberation (Renn and Schweizer 2009).

\subsection{Stakeholder Involvement in Risk Communication}

The need to involve stakeholders is particularly important when designing and implementing risk communication programs. Risk communication studies show that the credibility and trustworthiness of communicators can be enhanced if they build coalitions with highly esteemed stakeholders (Viklund 2003; Löftsedt 2005) If a risk communication program, for example, is cosigned by an industrial partner and an environmental nongovernmental organization, it will receive more respect and recognition among the targeted audiences than if the program comes from industry, an $\mathrm{NGO}$, or a regulator alone.

\section{Selecting Adequate Formats for Stakeholder Involvement}

Programs for stakeholder involvement should be designed in line with the complexity, uncertainty, and ambiguity of the risks, and in accordance with the phase of the risk governance cycle. Epistemic discourses are needed when there is high complexity, but low uncertainty and ambiguity. Such discourses are usually held during the appraisal stage. If the stakes are highly uncertain but less ambiguous, a reflective discourse is required. This discourse should take place during the phases of risk evaluation and management. If the risk issue is laden with ambiguity, a participatory discourse is the most appropriate strategy. This discourse can begin in the pre-assessment phase and continue through the entire cycle until risk management and communication.

This section outlines suggested formats for each of the three major discourse types explained above. Table 1 provides an overview of the three discourse strategies and lists the most appropriate formats (Renn 2008, p. 336ff; Aven and Renn 2010, p. 188ff; Renn 2014, p. 68ff).

\subsection{Formats for the Epistemic Discourse}

Resolving conflicts during the pre-assessment and assessment phase requires deliberation among knowledge holders. The formats listed in this category provide opportunities for experts (not necessarily scientists) to assess and discuss the main characteristics of the risk under investigation. The aim of an epistemic discourse is to find the most adequate description or explanation of a phenomenon (for example, which physical impacts are to be expected by the emission of specific substances?). Formats that promise to meet these requirements are expert hearings, expert workshops, science workshops, expert panels or advisory committees, or consensus conferences as practised in the medical field. If anecdotal knowledge is needed, one can refer to focus groups, panels of volunteers, and simple surveys. More sophisticated methods of reducing complexity for difficult risk issues include Delphi methods (explained below), group Delphi, meta-analytical workshops, and scoping exercises. The most frequently used formats for resolving conflicts about complex relationships are described in the following sections.

Expert Hearing This is the most popular form of resolving differences among knowledge carriers. Experts with different positions on the issue under discussion are asked to testify before the representatives of the organizing institution (most often a regulatory agency) or the deliberative panel. Each expert is asked a specific question. Occasionally, hearings allow for open discussions among the experts; but the final judgment is left to the organizing committee or the deliberative panel. Hearings are excellent and fairly inexpensive if the objective is to get a clearer picture of the variability of expert judgments and to become aware of the arguments supporting each position. Hearings do not provide consensus and may not resolve any conflict (Hadden 1989). However, they may clarify the basis of the conflict or the different 
Table 1 Appropriate formats for different risk discourse types

\begin{tabular}{|c|c|c|c|c|}
\hline & Challenge & Objective & Function & Instruments \\
\hline $\begin{array}{l}\text { Type } 1 \\
\text { epistemic }\end{array}$ & Complexity & $\begin{array}{l}\text { Inclusion of best } \\
\text { available knowledge }\end{array}$ & $\begin{array}{l}\text { Agreement on casual relations and } \\
\text { effective measures }\end{array}$ & $\begin{array}{l}\text { Expert panels, expert hearings, meta- } \\
\text { analysis, Delphi, and so on }\end{array}$ \\
\hline $\begin{array}{l}\text { Type } 2 \\
\text { reflective }\end{array}$ & Uncertainty & $\begin{array}{l}\text { Fair and acceptable } \\
\text { arrangement for benefit } \\
\text { and burden sharing }\end{array}$ & $\begin{array}{l}\text { Balancing costs of underprotection } \\
\text { versus costs of overprotection } \\
\text { facing uncertain outcomes }\end{array}$ & $\begin{array}{l}\text { Negotiated rule-making, mediation, } \\
\text { roundtables, stakeholder meetings, and so } \\
\text { on }\end{array}$ \\
\hline $\begin{array}{l}\text { Type } 3 \\
\text { participatory }\end{array}$ & Ambiguity & $\begin{array}{l}\text { Congruency with social } \\
\text { and cultural values }\end{array}$ & $\begin{array}{l}\text { Resolving value conflicts and } \\
\text { assuring fair treatment of concerns } \\
\text { and visions }\end{array}$ & $\begin{array}{l}\text { Citizen advisory committees, citizen panels } \\
\text { citizen juries, consensus conferences, } \\
\text { public meetings, and so on }\end{array}$ \\
\hline $\begin{array}{l}\text { Hybrid } \\
\text { designs }\end{array}$ & Combination & $\begin{array}{l}\text { Meeting more than one } \\
\text { challenge }\end{array}$ & $\begin{array}{l}\text { Meaningful and effective integration } \\
\text { of functions }\end{array}$ & $\begin{array}{l}\text { Selection from each of the three discourse } \\
\text { types }\end{array}$ \\
\hline
\end{tabular}

points of view in a contested risk issue. They are well suited for the first component of the analytic-deliberative approach-the analysis of facts and causal connections.

Expert Committees Expert committees, advisory boards, think tanks, and scientific commissions are also very popular forms of including external knowledge within the risk assessment and management process (Rich 2004). They have the advantage that experts interact freely with each other, have more time to learn from each other, and are able to consult other experts if deemed necessary. They work independently of the agency or deliberative body to which they report. The main disadvantage is that expert committees may not arrive at a consensus, may take too much time to reach a conclusion, or may not respond to the urgent needs of the deliberative body. In addition, many expert committees can only come to an agreement if the members have similar backgrounds and positions.

Expert Consensus Conference This method is particularly used in the medical field. Experts are gathered in a workshop to discuss treatment options and to decide on a general standard to be applied in comparable cases throughout the world (Jones and Hunter 1995). The workshop is organized in group sessions in order to prepare common standards, and in plenary sessions to reach a common agreement. Consensus conferences could be used in risk governance for the purpose of setting and articulating common conventions for risk assessment and evaluation.

Delphi Exercises A Delphi process is aimed at obtaining a wide range of opinions from a group of experts. The process is organized into four steps. In step one, a questionnaire is addressed to a group of scientists to assess the severity or the scope of a risk (Benarie 1988). The scientists provide their best assessments, possibly including some type of uncertainty interval with their answers. In step two, the scores of the whole group-including medians, standard deviation, and aggregated uncertainty intervals_-are fed back to each participant by the organizing team,. Each individual is then asked to perform the same task again, but now with the knowledge of the responses of all other participants. In step three, this procedure is repeated until individuals do not change their assessment any more. In the fourth and final step, the organizer should summarize the results.

A variation of the classic Delphi method is the group Delphi (Webler et al. 1991). During a group Delphi all participants meet face-to-face and their assessments are carried out in randomly assigned groups of three and four. The groups whose average scores deviate most from the median of all other groups are requested to defend their position in a plenary session. The small groups are then reshuffled and perform the same task again. This process can be repeated three or four times until no further significant changes are made. The advantage of Delphi is that a serious effort is invested in finding the common ground among the experts and in finding the reasons and arguments that cause differences in assessments. The disadvantage is that the quality of Delphi outcomes depends upon the accuracy and completeness of the expertise and information brought into the process.

\subsection{Formats for the Reflective Discourse}

The next set of methods is applicable to risk with high uncertainty, focusing on the impacts when balancing the pros and cons of different risk reduction methods. Scientific input is needed in order to compile the relevant data and the various arguments for different scientific camps. Information on the different types of uncertainties has to be collected and brought into a deliberative arena. The central objective is to deliberate over the prudent handling of unresolved uncertainty. For this purpose, representatives of affected stakeholders and public interest groups must be identified, invited, and informed about the issue in question. The objective of the deliberation is to find the right balance between too little and too much precaution. There is no scientific answer to this question, and even economic balancing procedures are of limited value since the stakes are 
uncertain. Major instruments for reflective discourses are roundtables, negotiated rule-making, mediation, arbitration, and stakeholder dialogues. The most popular instruments for conducting a reflective discourse within a deliberative setting are detailed in the following sections.

Stakeholder Hearings Most regulatory regimes throughout the world require hearings with stakeholders or directly affected citizens under specific circumstances (Checkoway 1981). Such hearings can serve a useful purpose if they are meant to give external stakeholders the opportunity to voice their opinions and arguments. Hearings also provide opportunities for stakeholders to understand the position of the regulatory agencies or other direct players (such as industry). However, hearings have proven quite ineffective for resolving conflicts or pacifying heated debates. On the contrary, hearings normally aggravate the tone of the conflict and lead to polarizations. Other than for the purpose of investigating the concerns and objections of organized groups, stakeholder hearings should be avoided.

Roundtables (Advisory Committees, Stakeholder Dialogues, and Negotiated Rule-Making) Roundtables are very popular settings for stakeholder involvement. Normally the participants represent major social groups (such as employers, unions, professional associations, and others). The advantage is that the ritual window-dressing activities (typical for classic hearings) can be overcome through the continuity of the process and a strict working atmosphere. The major disadvantage is that groups outside the roundtable and representatives of the general public are left out and they can only trust the process to be effective and fair (US-EPA/SAB 2001). If the debate is heated and adversarial elements govern the political climate, roundtables will face severe difficulties to legitimize their agreements. For many regulatory issues and risk management decisions, however, roundtables have been very effective and they are also cost-efficient in incorporating the perspectives of organized groups. There are also good techniques (such as value-tree analysis, multi-attribute decision-structuring, and meta-planning exercises) to make these group meetings more productive. Essential for a successful roundtable is the involvement of a professional moderator. It is advisable to have an independent service provider to moderate and facilitate the process, rather than the organizer.

Mediation (Arbitration and Alternate Dispute Resolution Methods) If conflicts are already clearly visible and unavoidable, the procedures of alternate dispute resolution are effective and less costly instruments compared to legal litigation. Mediation and similar procedures rest on the assumption that stakeholders can find a common solution if they do not insist on stubborn adherence to certain positions, but rather try to meet their crucial interests and underlying values (Baughman 1995). Under these circumstances, winwin solutions may be available that will please all parties. Mediation requires the involvement of a skilled and professional mediator. Similar to roundtables, such mediators should be recruited from neutral professional services. It is advisable that mediators have sufficient knowledge about the issue, that they can understand and evaluate all participants' statements, but that they do not have a clear commitment to any side. The advantage of mediation is that conflicts among participants can be reconciled before they reach the legal arena. The disadvantage is that, depending upon the composition of the group, interests that are not emphasized at the roundtable will not be considered.

Value-Tree Analysis A value tree identifies and organizes the values of an individual or group with respect to possible decision options. In the process of structuring a value tree, representatives of different stakeholder groups are asked to identify criteria and objectives for evaluating different options (von Winterfeldt 1987). A value tree structures the elicited values, criteria, and corresponding attributes in a hierarchy (with general values and concerns at the top and specific criteria and attributes at the bottom). Depending on the political context and the nature of the decision to be made, the values of the various stakeholder groups may vary considerably. By giving each group the right to assign a weight of 0 to each criterion that they regard irrelevant, it is possible to construct a joint or combined value tree that accounts for all viewpoints and can be verified by all participants. Value trees are helpful in structuring the underlying dimensions of a debate in order to link the general concerns of groups with concrete options. In this respect, value trees help to focus attention on issues that seem to underlie conflicts about the selection of options, and to develop a mediation program between conflicting groups. The joint tree can be used as a yardstick to evaluate different options and to select the most promising alternative. A value tree is a good tool to develop or to design new alternatives if all of the existing options perform poorly on the criteria specified by the value tree.

\subsection{Formats for the Participatory Discourse}

Other more participatory formats are required in the presence of high ambiguity. Most often, ambiguities arise over the issue of social or moral justification of a risky activity in the evaluation phase, and over the selection of the right management options, including the decision of who is to be responsible and accountable. Before investing in resolving ambiguity, it is essential to investigate the cause of the ambiguity and to find the right point at which the involvement procedure would best fit in the decision-making 
process. Preferred methods here are citizen panels or juries (randomly selected), citizen advisory committees or councils, public consensus conferences, citizen action groups, and other participatory techniques.

Public Hearings Public hearings are required in many regulatory regimes all over the world. The idea is that individuals who feel affected by a decision should be given an opportunity to make their concerns known to the authorities and, vice versa, to give the authorities the opportunity to explain their viewpoint to the public (Kemp 1985). Although public hearings are fairly inexpensive and easy to organize, their effectiveness is rated as poor in most of the scientific investigations on the subject. Hearings tend to stereotype the issue and the individuals involved, to aggravate emotions, to emphasize dissent rather than consensus, and to amplify distrust. Unless the issue is only slightly controversial and the climate is characterized by an overall consensual mood, most communication specialists do not recommend public hearings as a setting for resolving ambiguity.

Surveys and Focus Groups Surveys of the general public or special groups are excellent settings in which to explore the concerns and worries of the addressed audience. If they are performed professionally, the results are usually valid and reliable. However, the results of surveys provide only a temporary snapshot of public opinion; they do not produce solutions for conflict resolution or predict the fate of positions once they have entered the public arena. Surveys describe the starting position before a conflict may unfold.

Focus groups go one step further by exposing arguments to counter-arguments in a small group discussion setting (Dürrenberger et al. 1999). The moderator introduces a stimulus (for example, statements about the risk) and lets members of the group react to the stimulus and to each other's statements. Focus groups provide more than data about individuals' positions and concerns; they also measure the strength and social resonance of each argument vis-à-vis counter-arguments. The major disadvantage of surveys and focus groups is the lack of real interaction amongst the participants. Therefore, both formats are advisable as preliminary steps in understanding the context and the expectations; but they do not assist risk managers in resolving a pressing issue. In addition, both methods are fairly expensive.

Citizen Advisory Committees (Ombudsmen, Neighborhood Associations, Citizen Boards) The format of citizen advisory committees is particularly popular in local and regional contexts, but there are also examples for advisory committees on a national level. The chemical industry has been experimenting with citizen advisory committees for a long time in the framework of its responsible care program (Lynne and Kartez 1995). This program is directed towards people in the vicinity of chemical installations. Such an approach is also feasible with consumers if companies or agencies would like to involve their ultimate clients in the risk management process. The problem here is selection: one can either invite representatives of stakeholder groups (such as the consumer associations), or try to find a sample of "representative" consumers of the specific products or chemicals under review. Both approaches have merits and drawbacks. Stakeholder groups are often quite distanced from the members they are supposed to represent. This is particularly true for consumer associations since consumers form a very heterogeneous group, and the majority of them do not belong to consumer associations. At the same time, a representative sample of consumers is difficult to obtain, and it is questionable whether such a sample can speak in the interest of all consumers. In spite of these difficulties, such advisory committees can be very effective in detecting potential conflicts and getting the concerns of consumers heard and reflected in the respective organizing institutions. In addition, the organization of citizen advisory committees is fairly inexpensive and easy to perform.

Citizen Consensus Conferences The Danish Board of Technology introduced a new form of citizen involvement, which it called "consensus conferencing". This method is strongly based on the belief that a group of noncommitted and independent citizens is best to judge the acceptability or tolerability of technological risks (Joss 1998). Six to ten citizens are invited to study a risk issue in detail and to provide the legal decision-maker, or an agency, with a recommendation at the end of the process. The citizens are usually recruited by self-selection. The organizers put an advertisement in the newspaper asking for volunteers. If too many people volunteer for the consensus conference, the organizers follow specific rules for ensuring equal representation. An equal number of women and men are required, as well as a cross-section of the population in terms of age, social class, and political preferences. The participants receive a substantial amount of material to study before they convene for the first time. The consensus conference itself lasts 3 days. During the first day, the participants share their reflections with a body of regulators or decision-makers (often members of parliament). They also raise their questions and listen to the answers given by politicians and experts. The hearing continues on the second day, but this time it is open to the wider public. In the afternoon, the participants meet behind closed doors to articulate their recommendations. These are then presented to the decision-makers on the following day and the decision-makers have the opportunity to make further 
comments. Finally, the participants write the final draft of the recommendations and present them to the media at the end of the third day. The advantage of consensus conferencing is the transfer of a major conflict to a small group of laypeople, who are being educated about the subject and are asked to make recommendations based on their knowledge and personal values. The main disadvantage is the small number of people who are assigned such an important task. The restricted number of six to ten participants has been criticized. Consensus conferences seem to yield a compelling legitimacy effect within countries that are small and emphasize consensus over conflict. Most successful trials are reported in Denmark, Norway, and Switzerland. The experiences in more adversarial countries such as the UK, France, and Germany are less encouraging as the results of deliberations are not widely published in the media-decision-makers are not willing to submit sufficient time to small groups of laypeople, and administrators have paid only lip service to the conference statements (Renn 2008, p. 341).

Citizen Panels, Planning Cells, or Citizen Juries Planning cells or citizen panels (juries) are groups of randomly selected citizens who are asked to compose a set of policy recommendations on a specific issue (Dienel 1989). The objective is to provide citizens with the opportunity to learn about the technical and political facets of the risk management options, and to enable them to discuss and evaluate these options and their likely consequences according to their own sets of values and preferences. The participants are informed about the potential options and their consequences before they are asked to evaluate these options. Since the process requires time for the educational program and the evaluation of options, the panels are conducted in seminar form over 3-5 consecutive days. All participants are exposed to a standardized program to share information, which includes hearings, lectures, panel discussions, videotapes, and field tours. Since participants are selected by random procedures, every individual in the affected population has an equal opportunity to participate in the process. In reality, however, only $5-10 \%$ of the randomly selected citizens decide to become active participants (Renn and Schweizer 2009). In contrast to consensus conferences, however, the number of people, who can participate, is limited by available resources and time. Several hundred citizens can be involved in one exercise. All participants are grouped in panels of 20-25, with an identical educational program and evaluative tasks. If most of the panels come up with similar conclusions, one can be sure that this is (or would be) the will of the informed public. Planning cells require a large investment of time and money and are not suitable for all types of risk problems and all contexts. If the problem is highly technical, it may be impossible to bring citizens up to the necessary level of understanding. Furthermore, if the decision options are too narrowly restricted and there is not enough room to allow trade-offs on decision criteria, then the process will fail. Citizen panels may also face the problem of being legitimate consultants to policy-makers in an adversarial climate.

\subsection{Synthesis of Components: Design Discourse}

The three types of discourses with their respective formats provide a sufficient number of choices for matching the instrument with the risk problem at hand. It is more difficult, however, to find the right and appropriate combination if methods from several discourse types must be combined. For example, if risks are characterized by high complexity, uncertainty, and ambiguity, an integrated process is needed that includes a sequential chain consisting of at least one format from each pool. Or, if the risk is highly complex and uncertain but raises little controversy, only methods from discourse types 1 and 2 have to be selected. This implies that, in addition to an epistemic discourse, either a reflective or participatory discourse is added, depending on the degree of ambiguity associated with the risk debate.

Furthermore, selection of a specific sequence for stakeholder involvement depends upon the risk issue, the context, and the regulatory structure and culture of the country or state in which such a process is planned (Rowe and Frewer 2000). Different countries have diverse traditions and different preferences when it comes to deliberative processes. The selection of formats from the three pools, therefore, needs to reflect not only the combination of complexity, uncertainty, and ambiguity of the phase in the risk governance cycle, but also the specific requirement of the regulatory system and the respective political culture.

The requirements of an integrated sequence of formats are not met by merely running three or more different formats in parallel and feeding the output of each component as input into the next component. There is a need for continuity and consistency throughout the whole process. Several participants may be asked to take part in all formats in parallel, and an oversight committee may be necessary to provide the integrity of the entire process. Once the overall design has been drafted, it is essential to evaluate the process and the outcome of each segment within the sequence of formats so that corrections and revisions are still possible. There is no recipe book for stakeholder involvement. A convincing overall concept, an appropriate selection of corresponding formats, and the support of professional facilitators are all necessary, but are not sufficient conditions for a successful involvement process. 
Also needed are excellent listening skills and the flexibility to revise the process according to the needs of the participants.

\subsection{A Model for a Combination of Formats: The Cooperative Discourse Model}

The "cooperative discourse" model is a typical hybrid model of stakeholder involvement that combines selected formats of the three discourse types (Renn et al. 1993; Renn 2014, p. 76):

- Knowledge based on technical expertise (epistemic discourse; group Delphi format);

- Concerns, interests, and values derived from social interests and advocacy (reflective discourse; value-tree analysis format); and

- Preferences, concerns, and values based on common sense, folklore wisdom, and personal experience (participatory discourse; citizen panel format).

These three forms are integrated into a sequential procedure of three consecutive steps. The first step involves the identification of the objectives or goals that the process should reflect. The identification of concerns and objectives is best accomplished by asking all relevant stakeholder groups to share their values and criteria for judging different options (reflective discourse). This can be done by the value-tree analysis process, which provides a systematic overview of stakeholder concerns and values.

With different policy options and criteria available, the second step involves the actors with special knowledge and evidence on the subject. Experts representing multiple disciplines and plural viewpoints about the issue in question are asked to judge the performance of each option on each indicator (epistemic discourse). For this purpose, the group Delphi method is used.

The third and last step is the evaluation of each option profile by one group, or several groups of randomly selected citizens, in a participatory discourse. The idea is to conduct a loose process, analogous to a jury trial, with experts and stakeholders as witnesses and advisers on procedure as "professional" judges.

The whole process is supervised by a group of official policy-makers, major stakeholders, and moral agents (such as religious or cultural leaders). Their task is to oversee the process, test and examine the material handed out to the panelists, review the decision frames and questions, and write a final interpretation of the results.

One example of the cooperative discourse approach is a regional study that was conducted from 1994 to 1996 in the northern part of the Black Forest in southern Germany. The objective was to have stakeholders and citizens take part in planning a waste management program. A stakeholder dialogue based on the model of roundtables was organized in 1994 to develop waste reduction policies and to assess the recycling potential of the area (using the value tree method). The same group was also asked to find the most suitable technical solution for waste processing before final disposal. After these decisions were made, 200 randomly selected citizens from potential host communities were asked to find the most appropriate site for the types of facilities that had been previously chosen by the representatives of the roundtable. The most outstanding result was that panelists were even willing to approve a siting decision that would affect their own community. All ten citizen panels reached a unanimous decision based on agreement, which involved the recommendation to construct a small state-of-the-art incinerator in the center of the most populated town within the region. The reason for this surprising recommendation was that citizens wanted to present a visual reminder to their fellow citizens. They were not to forget the need to reduce waste, to burden those who contribute most to the problem, and to put the incinerator near the political power center as a "clever" means of ensuring compliance with environmental standards.

The application of the cooperative discourse method provides some evidence and reconfirms the fact that the theoretical expectations linked to the combination of epistemic, reflective, and participatory discourses can be met on local, regional, and national levels. Evaluation studies by independent scholars confirmed that the objectives of effectiveness, efficiency, and social acceptability were largely met in the cases in which this hybrid model was used.

\section{Conclusions}

The objective of this article has been to address and discuss the need and potential for stakeholder involvement in risk governance and to introduce different conceptual models of how to respond to the two crucial questions of any involvement process: Who and what should be included? And: What kind of output should the involvement process produce in order to facilitate better decision making? The article explained the requirements for involvement processes when approaching complex, uncertain, and ambiguous risk problems. Such risk problems require epistemic, reflective, and participatory discourse structures. For each of these discourse types appropriate formats are available that can be used to address the specific risk problem under investigation. Finally, stakeholder involvement needs to match the various phases of the risk governance cycle.

Recently, there has been much concern in the professional risk community that opening the risk management arena to stakeholder input would lead to a dismissal of factual knowledge and to inefficient spending of public money 
(Sunstein 2002). Given the experience with stakeholder involvement so far, these concerns are not warranted. There are only a few voices that wish to restrict scientific input to risk governance. Scientific expertise is an essential element of stakeholder involvement and a crucial pillar of all formats for stakeholder involvement. The role of scientific analysis in risk governance should not be weakened but, rather, strengthened when opening the arena for stakeholder input.

Profound scientific knowledge is required in risk governance, especially with regard to dealing with complexity. This knowledge has to be assessed and collected by scientists and risk professionals who are recognized as competent authorities in the respective risk field. The systematic search for the "state of the art" in risk assessment leads to a knowledge base that provides the data for deliberation. At the same time, however, the style of deliberation also should transform the scientific discourse and lead the discussion toward classifying knowledge claims, characterizing uncertainties, exploring the range of alternative explanations, and acknowledging the limits of systematic knowledge in many risk arenas. This can be done in any country, independent of political system, or governmental structure. Stakeholder involvement and public participation have been used and successfully implemented in many developing countries and threshold countries such as China (Grimble and Chan 1995; Tang et al. 2005).

Once the potential contributions of the expert communities, the stakeholder groups, and members of the affected public had been recognized and acknowledged in an adequate combination of formats, a process of mutual understanding and constructive decision-making started to unfold (Pahl-Wostl 2002). Such a discursive process may not always lead to the desired results, but the experiences so far justify a fairly optimistic outlook. The main lesson from these experiences has been that scientific expertise, rational decision-making, and public values can be reconciled if a serious attempt is made to integrate them. The transformation of the risk arena into a well-structured and professionally moderated analytic-deliberative discourse seems to be an essential and, ultimately, inevitable step towards improving risk policies and risk management.

Open Access This article is distributed under the terms of the Creative Commons Attribution License which permits any use, distribution, and reproduction in any medium, provided the original author(s) and the source are credited.

\section{References}

Aven, T., and O. Renn. 2010. Risk management and risk governance. Heidelberg: Springer.

Baughman, M. 1995. Mediation. In Fairness and competence in citizen participation. Evaluating new models for environmental discourse, ed. O. Renn, T. Webler, and P. Wiedemann, 253-266. Dordrecht: Kluwer Academic.

Benarie, M. 1988. Delphi and Delphi like approaches with special regard to environmental standard setting. Technological Forecasting and Social Change 33(2): 149-158.

Checkoway, B. 1981. The politics of public hearings. Journal of Applied Behavioral Science 17(4): 566-582.

Dienel, P.C. 1989. Contributing to social decision methodology: Citizen reports on technological projects. In Social decision methodology for technological projects, ed. C. Vlek, and G. Cvetkovich, 133-151. Dordrecht: Kluwer Academic.

Dreyer, M., and O. Renn. 2009. A structured approach to participation. In Food safety governance. Integrating science, precaution and public involvement, ed. M. Dreyer, and O. Renn, 110-120. Heidelberg: Springer.

Dürrenberger, G., H. Kastenholz, and J. Behringer. 1999. Integrated assessment focus groups: Bridging the gap between science and policy? Science and Public Policy 26(5): 341-349.

Entman, R.M. 1993. Framing: Toward clarification of a fractured paradigm. Journal of Communication 43(4): 51-58.

Grimble, R., and M.K. Chan. 1995. Stakeholder analysis for natural resources management in developing countries. Some practical guidelines for making management more participatory and effective. Natural Resources Forum 19(2): 113-124.

Hadden, S. 1989. A Citizen's right to know: Risk communication and public policy. Boulder: Westview Press.

Horlick-Jones, T. 1998. Meaning and contextualization in risk assessment. Reliability Engineering and Systems Safety 59(2): 79-89.

IRGC (International Risk Governance Council). 2005. Risk governance: Towards an integrative approach. White paper No. 1, IRGC, Geneva. http://www.irgc.org/IMG/pdf/IRGC_WP_No_1_ Risk_Governance_reprinted_version_.pdf. Accessed 2 Feb 2015.

IRGC (International Risk Governance Council). 2007. An introduction to the IRGC risk governance framework. Policy Brief, IRGC, Geneva.

Jones, J., and D. Hunter. 1995. Qualitative research: Consensus methods for medical and health services research. British Medical Journal 311(7001): 376-380.

Joss, S. 1998. Danish consensus as a model of participatory technology assessment: An impact study of consensus conferences on Danish parliament and Danish public debate. Science and Public Policy 25(1): 2-22.

Kemp, R. 1985. Planning, political hearings, and the politics of discourse. In Critical theory and public life, ed. J. Forester, 177-201. Cambridge: MIT Press.

Klinke, A., and O. Renn. 2012. Adaptive and integrative governance on risk and uncertainty. Journal of Risk Research 15(3): 273-292.

Klinke, A., and O. Renn. 2014. Expertise and experience: A deliberative system of a functional division of labor for postnormal risk governance. Innovation: The European Journal of Social Science Research 27(4): 442-465.

Löftsedt, R. 2005. Risk management in post trust societies. London: Palgrave Macmillan.

Lynne, F., and J.D. Kartez. 1995. The redemption of citizen advisory committees: A perspective from critical theory. In Fairness and competence in citizen participation. Evaluating new models for environmental discourse, ed. O. Renn, T. Webler, and P. Wiedemann, 87-102. Dordrecht: Kluwer Academic.

Pahl-Wostl, C. 2002. Participative and stakeholder-based policy design, analysis and evaluation processes. Integrated Assessment 3(1): 3-14.

Renn, O. 2008. Risk governance. Coping with uncertainty in a complex world. London: Earthscan. 
Renn, O. 2010. The contribution of different types of knowledge towards understanding, sharing and communicating risk concepts. Catalan Journal of Communication \& Cultural Studies 2(2): $177-195$.

Renn, O. 2014. Stakeholder involvement in risk governance. London: Ark Publications.

Renn, O., and P. Schweizer. 2009. Inclusive risk governance: Concepts and application to environmental policy making. Environmental Policy and Governance 19(3): 174-185.

Renn, O., A. Klinke, and M. van Asselt. 2011. Coping with complexity, uncertainty and ambiguity in risk governance: A synthesis. AMBIO 40(2): 231-246.

Renn, O., Th Webler, H. Rakel, P.C. Dienel, and B. Johnson. 1993. Public participation in decision making: A three-step-procedure. Policy Sciences 26(3): 189-214.

Rich, A. 2004. Think tanks, public policy, and the politics of expertise. New York: Cambridge University Press.

Rowe, G., and L.J. Frewer. 2000. Public participation methods: A framework for evaluation. Science, Technology and Human Values 25(1): 3-29.

Sunstein, C. 2002. Risk and reason. Cambridge: Cambridge University Press.
Tang, S.Y., C. Tang, and C. Wing-hung Lo. 2005. Public participation and environmental impact assessment in mainland China and Taiwan: Political foundations of environmental management. The Journal of Development Studies 41(1): 1-32.

US EPA/SAB (United States Environmental Protection Agency Science Advisory Board). 2001. Improved science-based environmental stakeholder processes. EPA-SAB-EC-COM01-006, EPA/SAB, Washington, DC.

van Asselt, M.B.A., and O. Renn. 2011. Risk governance. Risk Research 1(4): 431-449.

von Winterfeldt, D. 1987. Value tree analysis: An introduction and an application to offshore oil drilling. In Insuring and managing hazardous risks: From Seveso to Bhopal and beyond, ed. P.R. Kleindorfer, and H.C. Kunreuther, 349-385. Berlin: Springer.

Viklund, M.J. 2003. Trust and risk perception in Western Europe: A cross-national study. Risk Analysis 23(5): 727-738.

Webler, Th, D. Levine, H. Rakel, and O. Renn. 1991. A novel approach to reducing uncertainty: The group Delphi. Technological Forecasting and Social Change 39(3): 253-263. 